Article

\title{
POSS Nanofiller-Induced Enhancement of the Thermomechanical Properties in a Fluoroelastomer Terpolymer
}

\author{
Daphné Berthier ${ }^{1,2,3, *}$, Marie-Pierre Deffarges ${ }^{1}$, Nicolas Berton ${ }^{2}$, Mathieu Venin ${ }^{1}$, \\ Florian Lacroix ${ }^{1}$, Bruno Schmaltz ${ }^{2}$, Yohan Tendron ${ }^{3}$, Eric Pestel ${ }^{3}$, François Tran-Van ${ }^{2}$ and \\ Stéphane Méo ${ }^{1}$ (iD \\ 1 Laboratoire de Mécanique Gabriel Lamé, Université de Tours, Université d'Orléans, \\ INSA Centre Val de Loire, Polytech Tours, 7 avenue Marcel Dassault BP40, 37004 Tours, France; \\ marie-pierre.deffarges@univ-tours.fr (M.-P.D.); mathieu.venin@univ-tours.fr (M.V.); \\ florian.lacroix@univ-tours.fr (F.L.); stephane.meo@univ-tours.fr (S.M.) \\ 2 Laboratoire PCM2E (Physico-Chimie des Matériaux et des Electrolytes pour l'Energie), Université de Tours, \\ Parc de Grandmont, 37200 Tours, France; nicolas.berton@univ-tours.fr (N.B.); \\ bruno.schmaltz@univ-tours.fr (B.S.); francois.tran@univ-tours.fr (F.T.-V.) \\ 3 Zodiac Aerosafety Systems, 20 avenue Georges Pompidou, 37600 Loches, France; \\ yohan.tendron@zodiacaerospace.com (Y.T.); eric.pestel@zodiacaerospace.com (E.P.) \\ * Correspondence: berthier.daphne@gmail.com; Tel.: +33-247-361-319
}

Received: 3 July 2018; Accepted: 3 August 2018; Published: 6 August 2018

check for updates

\begin{abstract}
The present study reports on the use of three types of polyhedral oligomeric silsesquioxanes (POSS) nanoparticles with various organic substituents as fillers in a fluoroelastomer (FKM). A series of/POSS elastomer composite thin films is prepared. Microstructural SEM/TEM (scanning electron microscopy/transmission electron microscopy) imaging reveals a dispersion state allowing the presence of micron-sized domains. The influence of POSS content is studied in order to optimize thermal stability and mechanical properties of the composite thin films. Both POSS-A (with an acryloyl functional group and seven isobutyl substituents) and POSS-P (with eight phenyl substituents) lead to higher thermal stability and modulus of the composites, with respect to the unfilled FKM terpolymer matrix. covalent grafting of POSS-A onto the FKM network is found to play a critical role. Enhanced storage modulus in the rubbery plateau region $\left(+210 \%\right.$ at $200{ }^{\circ} \mathrm{C}$ for $20 \mathrm{phr}$ ) suggests that POSS-A is particularly suitable for high temperature applications.
\end{abstract}

Keywords: POSS; nanofillers; FKM; rubber; terpolymer; thermomechanical properties

\section{Introduction}

Since their first use, fluoroelastomers (FKM) have become of great interest. They are used for many applications in the building (as paints and coatings resistant to UV and graffiti), petrochemical and automotive industries, aerospace, and aeronautics (use of elastomers as seal, gasket or O-ring to be used in extreme temperatures for liquid hydrogen storage in space shuttles), chemical engineering (high-performance membranes), optics (core and cladding of optical fibers), and treatment of textiles [1]. This polymeric family includes different kinds of products with specific properties, such as thermoplastics and elastomers [1]. Fluorinated FKM terpolymers consisting of vinylidene fluoride (VDF), hexafluoropropylene (HFP), and tetrafluoroethylene (TFE) monomer units can be either amorphous or semi-crystalline depending upon the monomers ratio [2]. Their specificity consists of a unique combination of properties including good thermal aging, weather, and chemical resistances, low surface energy, low inflammability, and low moisture absorption $[3,4]$. These properties can be 
explained by a low polarizability and a strong electronegativity provided by fluorine atoms leading to low molecular motions and high bond energy [5].

However, improving the resistance of FKM based terpolymer is still required as they exhibit chemical degradation as well as thermal degradation at high temperature in demanding environment. This involves oxidation and thermolysis of the polymer that can occur on vinylidenefluoride groups and cross-linking bonds [6,7]. A way to further improve thermal properties of FKM is to integrate nanoparticles. Indeed, this general process seems to be the simplest mean to enhance various rubber characteristics, including thermal resistance [8]. A major advantage of nanocomposites is that a low fillers content is sufficient to improve their properties $[9,10]$. The tensile resistance of natural rubbers is for instance found to increase from around $5 \mathrm{MPa}$ with carbon black (10 phr: per hundred rubber), up to $15 \mathrm{MPa}$ with nanoclay (10 phr) [11]. In particular, the presence of nanofillers was found to lead to higher cross-linking density upon vulcanization.

Polyhedral oligomeric silsesquioxanes (POSS) nanoparticles are particularly attractive as nanofillers. They were first developed by the United States Air Force for aerospace applications [12]. Scott [13] isolated the first $\left(\mathrm{CH}_{3} \mathrm{SiO}_{1.5}\right)_{\mathrm{n}}$ oligomers in 1946, with other volatile compounds, by thermolysis of polymer products obtained from methyltrichlorosilane and silane dimethylchloro-cohydrolysis. POSS is described as a cubic cage with a silicon-to-oxygen ratio of 1:1.5, organic peripheral groups at each silicon atom [14,15], and a molecular diameter of around 1-3 nm [8]. The number and nature of functional groups present on the POSS corners lead to different kinds of interactions with the matrix $[16,17]$. These nanoparticles are very adaptable and can be fully designed to the convenience of the user. In the absence of functional groups, POSS behave as a classical filler interacting with the matrix through physical interactions. On the other hand, POSS can be chemically grafted as pendant units on macromolecular chains with functional groups on its periphery [18]. When two functional groups are present, POSS can be used as a cross-linking agent leading to tridimensional networks. Currently, incorporation of POSS into polymers increases the oxidative resistance, the glass transition temperature, and the composite stiffness. Various types of POSS have been used with PDMS [19-24] or natural rubber matrix [25]. Despite few promising findings, applications with a FKM matrix are much less well described. The amount of fillers required to obtain an efficient level of reinforcement is likely to depend on the mixture and the application. A $48 \%$ increase of elongation at break and $93 \%$ increase of the tensile at break were reported, with only $5 \mathrm{phr}$ of POSS functionalized with hydroxyl functional groups [26]. In another work, a mixture with $12 \mathrm{phr}$ (per hundred rubber) of POSS with propyl methacrylate on its periphery, resulted in an increase by $10 \%$ of the temperature at $2 \%$ of weight loss measured by thermogravimetric analysis (TGA) [27].

Here, three kinds of POSS nanoparticles, differing by their organic substituents, are used as nanofillers in a (HFP-TFE-VDF) fluoroelastomer terpolymer. The influence of specific POSS/FKM interactions on the FKM network structure and the thermal stability of the composites is studied for each type of POSS. The most appropriate fillers are selected and the amount is optimized in order to enhance the thermomechanical properties of the fluoroelastomer composites. The covalent grafting of POSS onto the fluoroelastomer network is found to lead to significant improvement.

\section{Materials and Methods}

\subsection{Materials}

The matrix was a FKM terpolymer (HFP-TFE-VDF) provided by DuPont $\odot$ (Wilmington, DE, USA), and it contained a tiny amount of barium sulfate. The crosslinking system was formed by an organic peroxide coupled with a crosslinking coagent. The peroxide was a diacyl peroxide Norperox DBPH-45 (NODMANN, RASSMANN GMBH, Hamburg, Germany), with silicone carbonate as phlegmatizer (2,5-Dimethyl-2,5-di-(ter-butylperoxy)hexane). The coagent was used to enhance the crosslinking process, the heat resistance and mechanical properties, with calcium carbonate as a phlegmatizer (triallylisocyanurate Norlink TAIC 70 CS, (NODMANN, RASSMANN GMBH, Hamburg, 
Germany) Three types of POSS ( $\left.\mathrm{RSiO}_{1.5}\right)_{\mathrm{n}}$ were used: POSS-P Octaphenyl, POSS-F Trifluoropropyl and POSS-A Acryloisobutyl provided by Hybrid Plastics (Hattiesburg, MS, USA). POSS-F has a $\mathrm{T}_{12}$ cage structure (bearing 12 trifluoropropyl moieties $\left(\mathrm{CF}_{3}-\right)$ ), POSS-P possesses a $\mathrm{T}_{8}$ structure (with eight phenyl moieties $\left.\left(\mathrm{C}_{6} \mathrm{H}_{5}-\right)\right)$ and POSS-A has a $\mathrm{T}_{8}$ structure (with seven isobutyl moieties $\left(\mathrm{C}_{4} \mathrm{H}_{9}-\right.$ ) and an acrylo functional group $\left.\left(-\mathrm{C}_{6} \mathrm{O}_{2} \mathrm{H}_{10}\right)\right)$. The three POSS have the appearance of a white powder.

\subsection{Compounding and Vulcanization Procedure}

The nanocomposites were prepared by solution casting (Hand Coater). The ingredients were dispersed in acetone by magnetic stirring at room temperature in the following integration order: POSS, crosslinking system, and finally the matrix. The matrix solution concentration is $383 \mathrm{~g} / \mathrm{L}$. For each POSS, five loadings were studied: 5, 10, 15, 20, and $40 \mathrm{phr}$ (per hundred rubber).

The composite designation was: $-\mathrm{F}$ for the FKM gum; $-\mathrm{F}_{\mathrm{R}}$ for the mixture of FKM gum and the crosslinking system; $-\mathrm{F}_{\mathrm{T}}$ for the mixture of gum, the crosslinking system, and POSS fillers, following by the POSS type (A, F, or P) and the rate. For example: the $\mathrm{F}_{\mathrm{T}}$ composite with POSS-A at 15 phr was called: $\mathrm{F}_{\mathrm{TA}-15}$.

Rubber elaboration was carried out in thin films $(350-400 \mu \mathrm{m})$, processing from solution using a Hand Coater (Elcometer 4340, elcometer ${ }^{\circledR}$, Manchester, UK) and dried for 13 days at room temperature [28]. One should note that only crosslinker containing samples were cured. During vulcanization, the samples were heated for $45 \mathrm{~min}$ at $150{ }^{\circ} \mathrm{C}$, followed by post-curing at $180^{\circ} \mathrm{C}$ for six hours, under an air atmosphere.

\subsection{Characterization}

A Zeiss field emission model Ultra Plus Scanning Electron Microscope (SEM) (Carl Zeiss Microscopy, Oberkochen, Germany), operating at $5 \mathrm{kV}$, was used to examine the nanocomposites surface micro-structure and analyze particle dispersion. The samples are cleaved with a sharp razor and coated with a Platinum film to increase electrical conductivity. A Transmission Electron Microscopy (TEM) (JEOL 1230, 120kV, JEOL USA, Inc., Peabody, MA, USA) was used to observe the particle dispersion inside the nanocomposite. The nanoparticles were dispersed in acetone, drop-casted on carbon coated copper grid, and were analyzed under an accelerating electron beam, after solvent evaporation. Cured nanocomposites were ultramicrometered using a diamond knife at $-40{ }^{\circ} \mathrm{C}$ with a Leica Ultracut UCT (Leica Microsystemes SAS, Nanterre, France). These ultra-thin sections were then transferred onto a copper grid covered with a very thin film of amorphous carbon.

Differential scanning calorimetry (DSC) was performed under a nitrogen atmosphere on a Netzch Instruments (DSC 200 F3, Netzch, Selb, Germany). The accuracy of the measures was $\pm 1{ }^{\circ} \mathrm{C}$. Samples are cooled down to $-140{ }^{\circ} \mathrm{C}$ and heated up to $250{ }^{\circ} \mathrm{C}$ at $20^{\circ} \mathrm{C} \cdot \mathrm{min}^{-1}$. A second cooling was performed from $-80{ }^{\circ} \mathrm{C}$ to $250^{\circ} \mathrm{C}$ at $20^{\circ} \mathrm{C} \cdot \mathrm{min}^{-1}$. Systematically, two DSC measurements have been performed on each samples. The averaged values of glass transition temperature $\left(\mathrm{T}_{\mathrm{g}}\right)$ and of cross-linking reaction enthalpy $(\Delta \mathrm{H})$ were reported. Thermal gravimetric analysis (TGA) is performed using a Mettler-Toledo instrument (TGA-2, Mettler-Toledo, Columbus, IN, USA). Samples are characterized under two different atmospheres. For the first procedure, samples were heated from $25^{\circ} \mathrm{C}$ to $600{ }^{\circ} \mathrm{C}$ under nitrogen atmosphere, then from $600{ }^{\circ} \mathrm{C}$ to $800{ }^{\circ} \mathrm{C}$ under air, at $20{ }^{\circ} \mathrm{C} \cdot \mathrm{min}^{-1}$. For the second procedure, samples are heated from $25^{\circ} \mathrm{C}$ to $800{ }^{\circ} \mathrm{C}$ under air at $20^{\circ} \mathrm{C} \cdot \mathrm{min}^{-1}$. $\mathrm{T}_{\text {onset }}$ (extrapolated starting temperature, intersection, point of the baseline before a thermal effect and tangent), $\mathrm{T}_{5 \%}$, $\mathrm{T}_{20 \%}$ (temperature for 5 and $20 \%$ of weight loss) and $\mathrm{T}_{50 \%}$ (temperature of peak decomposition of the derivative curve) are measured. Theoretical ashes are calculated assuming a complete conversion of POSS to $\mathrm{SiO}_{2}$. The residues (in percent) calculated from each thermogram are also given. These residues correspond to ash content remaining after measurement. An average of three independent measurements was reported. 
The dynamic mechanical properties were analyzed with a thermal analysis instrument (DMA 2980 TA Instrument Dynamic Mechanical Analyzer; TA Instruments, New Castle, PA, USA). Test specimens were taken from the post-cured thin film (width $9 \mathrm{~mm}$, distance between clamping $10 \mathrm{~mm}$ ) and were submitted to a tension mode. Temperature sweeps were carried out over a temperature range from $-30{ }^{\circ} \mathrm{C}$ to $250{ }^{\circ} \mathrm{C}\left(3^{\circ} \mathrm{C} \cdot \mathrm{min}^{-1}\right)$ at a constant frequency $(1 \mathrm{~Hz})$ and with an amplitude of displacement of $\pm 0.5 \mu \mathrm{m}$. An average value of three independent measurements was reported: the glass transition temperature $T_{g}$ taken at the maximum phase angle between stress and strain $(\tan \delta)$, $\tan \delta$ at $\left(\mathrm{T}=\mathrm{T}_{\mathrm{g}}\right)$, and the storage modulus $\left(\mathrm{E}^{\prime}\right)$ at $100^{\circ} \mathrm{C}$ and at $200^{\circ} \mathrm{C}$.

A universal testing machine (Zwick $1 \mathrm{kN}$; Zwick Roell Group, Ulm, Germany) with computerized recording was used at room temperature to obtain the mechanical properties. The tests were carried out at a crosshead speed of $1 \mathrm{~mm} / \mathrm{min}$ (or $\dot{\varepsilon}=0.083 \% / \mathrm{s}$ ), and an average of at least 10 measurements for each compound was recorded. The test dumbbell-shaped specimens were taken from the post-cured thin film with a specific tensile specimen cutter developed in our laboratory, in order to optimize the mechanical response of the thin film on the test machine, and to enlarge the clamping area of the dumbbell-shaped specimens. The useful length and the width of dumbbell-shaped specimens is respectively $15 \mathrm{~mm}$ and $2 \mathrm{~mm}$ (Figure 1). The averaged values of tensile at break, elongation at break, and moduli at $10 \%$ and at $100 \%$ of deformation are reported.

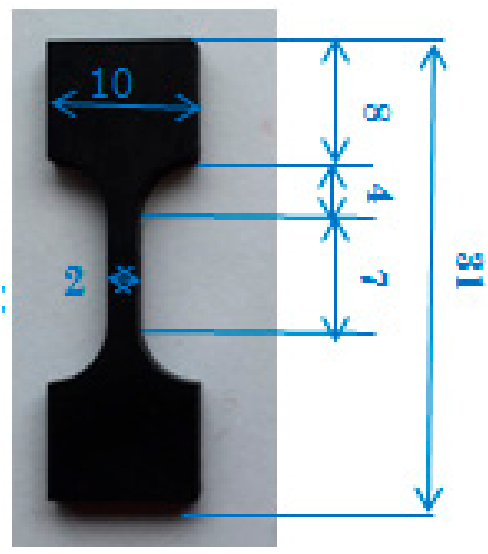

Figure 1. Dumbbell-shaped specimens developed in our laboratory.

\section{Results and Discussion}

\subsection{Composition and Fabrication of Composite Films}

The chemical structure of the FKM was composed of three monomers: $\operatorname{HFP}\left(\mathrm{CF}_{2} \mathrm{CF}\left(\mathrm{CF}_{3}\right)\right)$, TFE $\left(\mathrm{CF}_{2} \mathrm{CF}_{2}\right)$ and VDF $\left(\mathrm{CH}_{2} \mathrm{CF}_{2}\right)$. The various POSS investigated in this study are shown in Scheme 1. Specific interactions with the FKM could be expected for each type of POSS. POSS-A was likely to be covalently grafted on the FKM due to the presence of a reactive acryloyl functional group on its surface, while POSS-P and POSS-F only led to physical interactions of different strengths. In particular, the presence of fluorinated moieties on POSS-F provided improved chemical compatibility with the (HFP-TFE-VDF) terpolymer. The POSS-containing nanocomposites based on FKM were obtained as thin films (350-400 $\mu \mathrm{m}$ thick) using doctor blade coating. The vulcanization process was then performed, as described in the experimental section. 




(a)

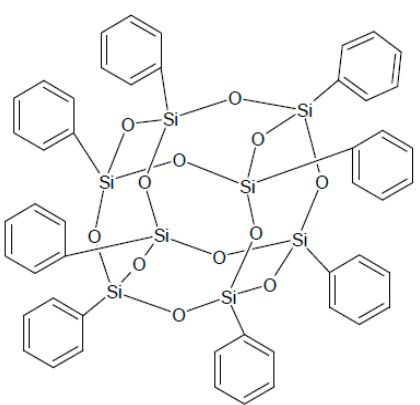

(b)

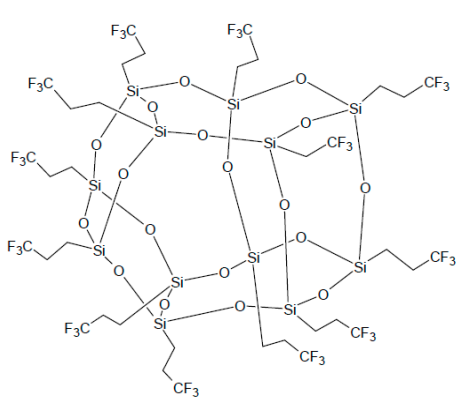

(c)

Scheme 1. Chemical structure of: (a) POSS-A; (b) POSS-P and (c) POSS-F.

\subsection{Evaluation of the Dispersion State}

The distribution of fillers can influence the properties of the final products. Microstructural analysis was performed using transmission (TEM) and scanning (SEM) electron microscopy in order to determine the particles size, dispersion state, and the morphology of the nanocomposites.

SEM micrographs depict the surface of the three nanocomposite films (Figure 2). SEM images of the FKM polymer matrix F (Figure S1), and of the vulcanized matrix $F_{R}$ (Figure S2) are shown for comparison. The composites obtained with POSS-A $\left(\mathrm{F}_{\mathrm{TA}}\right)$ and POSS-P $\left(\mathrm{F}_{\mathrm{TP}}\right)$ exhibited a smooth surface morphology, whereas $\mathrm{F}_{\mathrm{TF}}$ nanocomposite films presented a heterogeneous surface, with cracked and lamellar zones. This can be attributed to low filler/matrix compatibility. In $\mathrm{F}_{\mathrm{TA}}$ and $\mathrm{F}_{\mathrm{TP}}$ composites, the charges seemed well dispersed, indicating a better compatibility with the FKM. The typical micrometer-sized POSS-A crystals with rectangular faces were observed on TEM images (Figure S3) are visible at the surface of the $\mathrm{F}_{\mathrm{TA}}$ film (Figure $2 \mathrm{~b}$ ), while, crystalline phases are not evidenced from SEM images in $\mathrm{F}_{\mathrm{TP}}$ and $\mathrm{F}_{\mathrm{TF}}$ films (Figure $2 \mathrm{~d}, \mathrm{f}$ ).

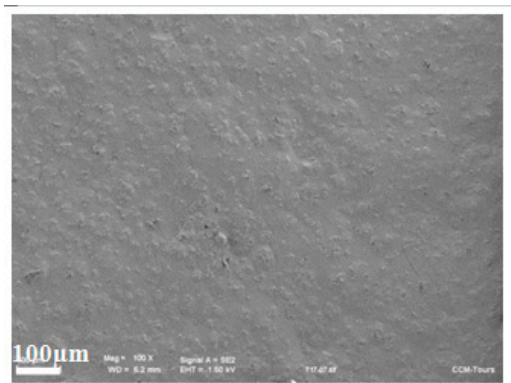

(a)



(b)

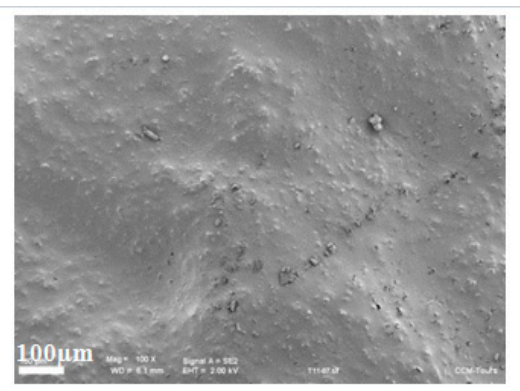

(c)



(d)

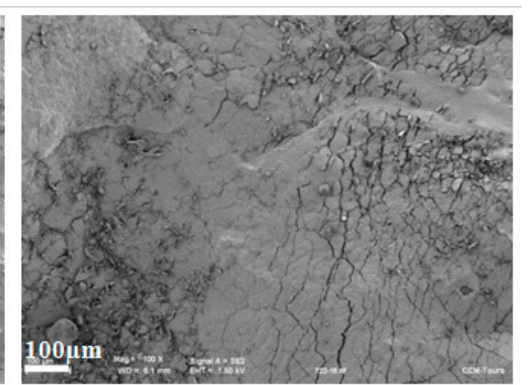

(e)

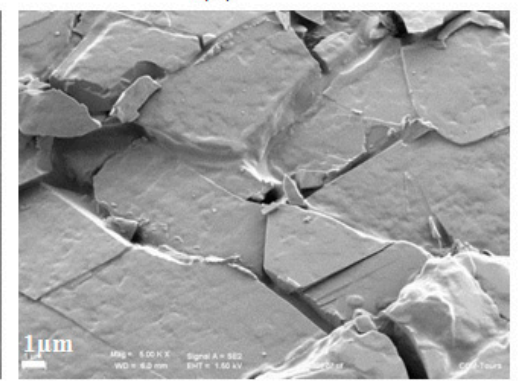

(f)

Figure 2. Scanning electron microscopy (SEM) micrographs of POSS nanocomposites. (a,b) $\mathrm{F}_{\mathrm{TA}-20}$; (c,d) $\mathrm{F}_{\mathrm{TP}-20} ;(\mathbf{e}, \mathbf{f}) \mathrm{F}_{\mathrm{TF}-20}$ (POSS content 20 phr).

In order to investigate the fillers dispersion within the matrix, TEM micrographs were recorded on ultra-thin sections of the nanocomposite films containing POSS-A, POSS-P, or POSS-F at a loading 
ratio of $10 \mathrm{phr}$ (Figure 3). The observed small dark particles came from the FKM polymer gum (Figure S4), and large bright domains $(>10 \mu \mathrm{m})$ could be attributed to crosslinking system aggregates dispersed in the matrix (Figure S5). To identify these particles, energy dispersive X-ray spectrometry (EDX, Carl Zeiss Microscopy, Oberkochen, Germany) studies were performed. In the black particles zones, sulfur, oxygen, and barium chemical elements were detected (Figure S6) and thus may correspond to barium sulfate. This ingredient was added into the rubber matrix in order to avoid coalescence by agglomeration during the polymerization. In the aggregate zones, silicon and carbon elements were identified (Figure S7), thus confirming their assignment to crosslinking system compounds. Indeed, it was fixed on an inert support, including the detected elements. POSS particles aggregates exhibit both dark and bright spots, likely due to different crystal orientations. The POSS dispersion state within the bulk nanocomposites can be deemed acceptable since POSS aggregates are smaller than aggregates related to cross-linking agents $(<10 \mu \mathrm{m})$.

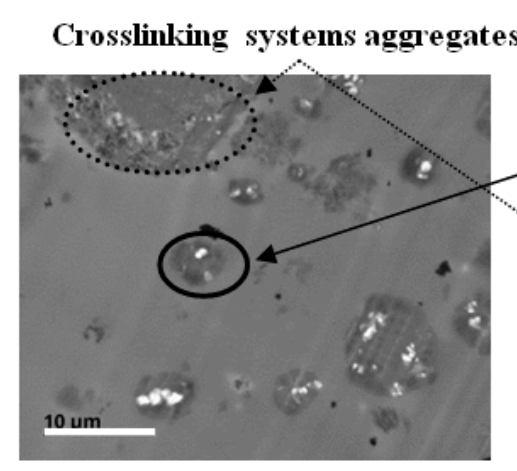

(a)

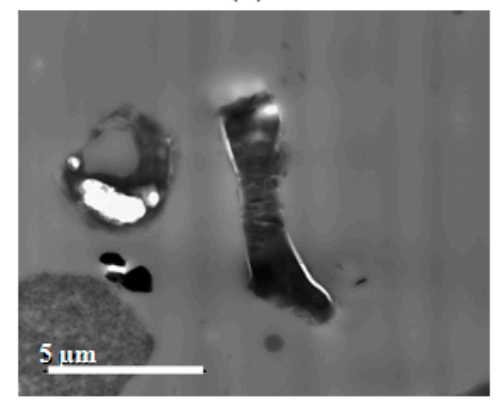

(b)

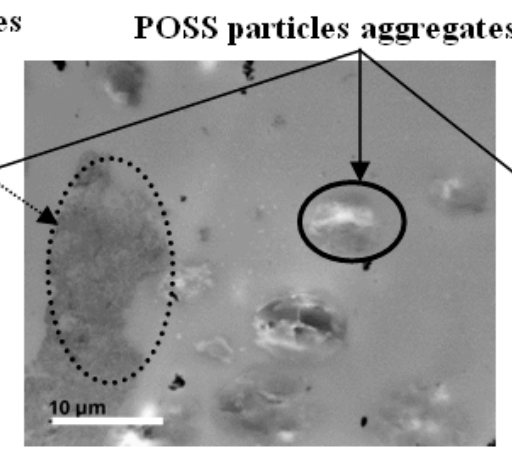

(c)

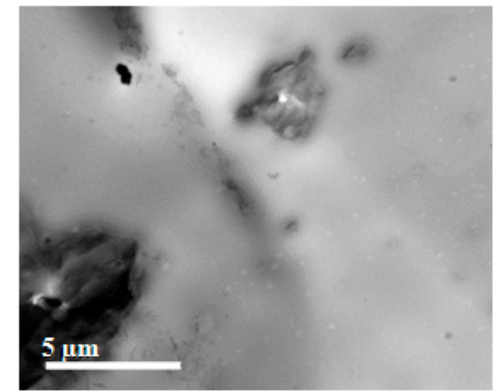

(d)
Barium sulfate particles

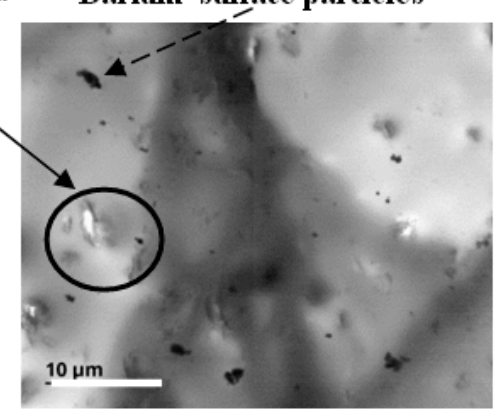

$(\mathbf{e})$

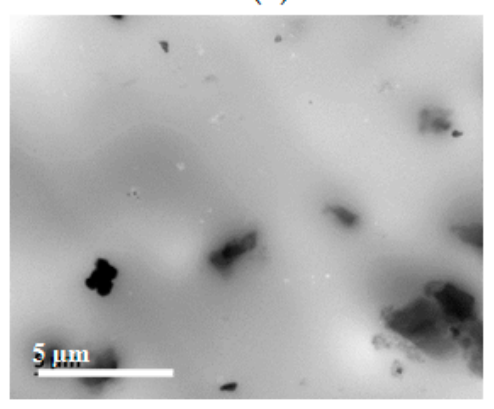

(f)

Figure 3. Transmission electron microscopy (TEM) micrographs of POSS nanocomposites. $(\mathbf{a}, \mathbf{b}) \mathrm{F}_{\mathrm{TA}-20}$, (c,d) $\mathrm{F}_{\mathrm{TP}-20},(\mathbf{e}, \mathbf{f}) \mathrm{F}_{\mathrm{TF}-20}$ (POSS content $20 \mathrm{phr}$ ).

\subsection{Thermal Characterization}

The thermal properties of the composites were characterized by DSC and TGA for different POSS loadings.

\subsubsection{DSC}

To understand the impact of POSS incorporation, DSC measurements were carried out on the raw composite mixtures, and on the vulcanized nanocomposites. A glass transition temperature $\left(\mathrm{T}_{\mathrm{g}}\right)$ was clearly observed in all cases (Figure 4). The exothermic peaks that were observed upon heating of the raw composite films could be attributed to the thermally activated cross-linking reaction. The corresponding heat of reaction $(\Delta \mathrm{H})$ was measured from its peak area. Data are summarized in Table 1 . 




(a)

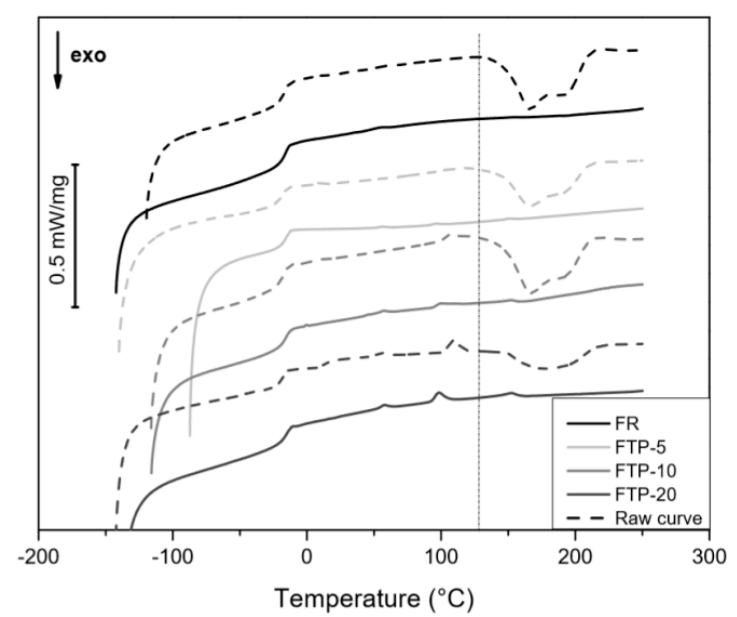

(b)

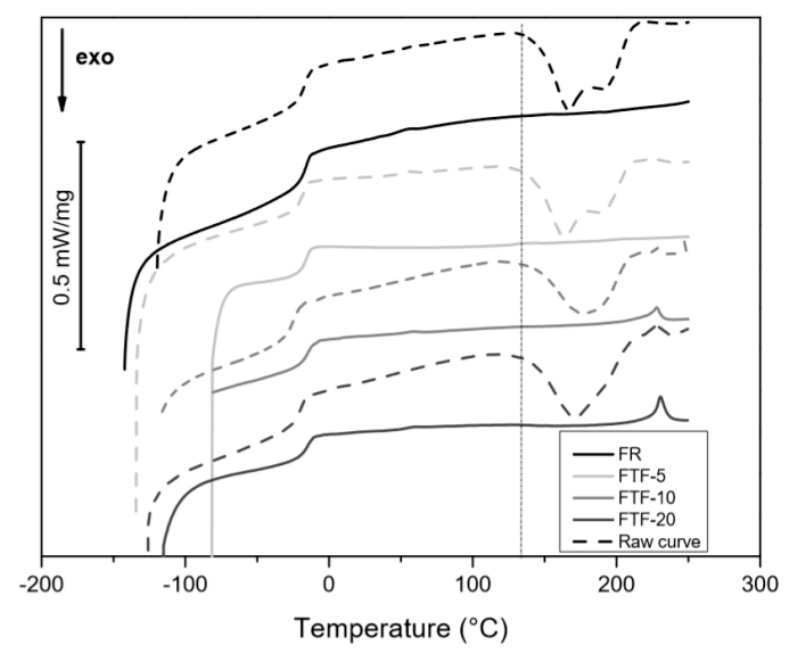

(c)

Figure 4. Differential Scanning Calorimetry (DSC) curves of raw and cured $\mathrm{F}_{\mathrm{T}}$ nanocomposites: (a) $\mathrm{F}_{\mathrm{TA}}$, (b) $\mathrm{F}_{\mathrm{TP}}$, and (c) $\mathrm{F}_{\mathrm{TF}}$ at a heating rate of $20^{\circ} \mathrm{C} \cdot \mathrm{min}^{-1}$.

Table 1. Summary of $\mathrm{T}_{\mathrm{g}}$ and $\Delta \mathrm{H}$ of the composites ( $\mathrm{T}_{\mathrm{g}}$ and $\Delta \mathrm{H}$ are reported in ${ }^{\circ} \mathrm{C}$ and $\mathrm{J} / \mathrm{g}$, respectively).

\begin{tabular}{|c|c|c|c|c|c|c|c|c|c|c|c|c|}
\hline \multicolumn{3}{|c|}{$F_{R}$} & \multirow{3}{*}{$\begin{array}{c}\text { phr } \\
-\end{array}$} & \multicolumn{3}{|c|}{$\mathrm{F}_{\mathrm{TA}}$} & \multicolumn{3}{|c|}{$\mathrm{F}_{\mathrm{TP}}$} & \multicolumn{3}{|c|}{$\mathrm{F}_{\mathrm{TF}}$} \\
\hline \multicolumn{2}{|c|}{ Raw } & \multirow{2}{*}{$\begin{array}{c}\text { Vulcanized } \\
T_{g}\end{array}$} & & \multicolumn{2}{|c|}{ Raw } & \multirow{2}{*}{$\begin{array}{c}\text { Vulcanized } \\
T_{g} \\
\end{array}$} & \multicolumn{2}{|c|}{ Raw } & \multirow{2}{*}{$\begin{array}{c}\text { Vulcanized } \\
T_{g} \\
\end{array}$} & \multicolumn{2}{|c|}{ Raw } & \multirow{2}{*}{$\begin{array}{c}\text { Vulcanized } \\
T_{g} \\
\end{array}$} \\
\hline $\mathrm{T}_{\mathrm{g}}$ & $\Delta \mathrm{H}$ & & & $T_{g}$ & $\Delta \mathrm{H}$ & & $T_{g}$ & $\Delta \mathrm{H}$ & & $T_{g}$ & $\Delta \mathrm{H}$ & \\
\hline-16.8 & -24.6 & -16.2 & $\begin{array}{c}5 \\
10 \\
15 \\
20\end{array}$ & $\begin{array}{l}-18.8 \\
-21.0 \\
-19.7 \\
-16.1\end{array}$ & $\begin{array}{l}-30.8 \\
-22.7 \\
-23.7 \\
-23.3\end{array}$ & $\begin{array}{l}-15.6 \\
-16.5 \\
-14.8 \\
-16.5\end{array}$ & $\begin{array}{l}-18.8 \\
-17.4 \\
-17.1 \\
-18.1\end{array}$ & $\begin{array}{l}-20.5 \\
-24.1 \\
-15.6 \\
-13.7\end{array}$ & $\begin{array}{l}-16.2 \\
-16.7 \\
-16.4 \\
-15.8\end{array}$ & $\begin{array}{l}-16.4 \\
-22.6 \\
-20.5 \\
-19.7\end{array}$ & $\begin{array}{l}-21.7 \\
-18.2 \\
-22.3 \\
-22.9\end{array}$ & $\begin{array}{l}-14.4 \\
-14.6 \\
-15.5 \\
-15.9\end{array}$ \\
\hline
\end{tabular}

POSS filling was found to have only a limited influence on the glass transition temperature. The glass transition of the unfilled FKM matrix $\mathrm{F}_{\mathrm{R}}$ was $-16.8^{\circ} \mathrm{C}$ and it increased very slightly to $-16.2{ }^{\circ} \mathrm{C}$ upon vulcanization. With the presence of POSS, the $\mathrm{T}_{\mathrm{g}}$ of the raw composites was slightly lower, regardless of POSS surface functional group and content. This indicates that POSS particles acted mainly as plasticizers, bringing additional free volume. At a higher POSS content ( $>10 \mathrm{phr})$, it can be noticed that the $\mathrm{T}_{\mathrm{g}}$ increased again with POSS-A and POSS-F, which may be related to a competing effect of POSS/FKM interactions [29]. However, these variations remained small compared with some previous reports where the $\mathrm{T}_{\mathrm{g}}$ of POSS-containing polymers was found to be strongly dependent on the nature of surface functional groups present on POSS particles [27,30]. This suggests that intermolecular interactions between fillers and FKM were weak. Vulcanization of the composites 
led to a noticeable increase of $T_{g}$ that canceled the plasticizing effect of the filler. The average $T_{g}$ values measured on the vulcanized samples were all analogous to, or even slightly higher than the $T_{g}$ of the FKM matrix. The accuracy of the measure $\left( \pm 1^{\circ} \mathrm{C}\right)$ did not allow to a particular trend related to the POSS type or amount in the composite to be determined.

The cross-linking reaction can be evaluated from the area under the exothermic peaks. The $\Delta \mathrm{H}$ values recorded for $\mathrm{F}_{\mathrm{TP}}$ compounds decreased when the filler content increased, indicating that POSS-P particles hamper the cross-linking reaction. It can also be noticed that the onset of the exothermic reaction peak was shifted toward higher temperature $\left(c a .+10{ }^{\circ} \mathrm{C}\right.$ at $20 \mathrm{phr}$ loading) (Figure $4 \mathrm{~b}$ ). On the contrary, the vulcanization process showed little sensitivity to the presence of POSS-F (Figure 4c). The temperature at which cross-linking was initiated remained unchanged, and $\Delta \mathrm{H}$ (in J/g of matrix) was close to those measured for the FKM matrix $F_{R}$. The vulcanization of $F_{R A}$ compounds exhibited a more complex behavior. Upon the incorporation of POSS-A, a shift towards low temperatures appeared in the crosslinking area on the thermograms in addition to the characteristic exothermic cross-linking peaks, and exothermic reactions started at a lower temperature (onset was shifted from $145^{\circ} \mathrm{C}$ to $125^{\circ} \mathrm{C}$ ) (Figure 4a). This phenomenon could be associated with the grafting of POSS particles on the polymer chains through the reactive acryloyl groups. As a consequence, the heat of reaction was strongly enhanced at a loading of $5 \mathrm{phr}$. Fillers act as an inductive donor effect; the chains are more reactive and this could explain $\Delta \mathrm{H}$ increase. However, it was noticed that $\Delta \mathrm{H}$ decreases at a higher loading. This could be due to a steric hindrance induced by POSS-A particles that act as a shield because of the inductive attractor effect. There is most likely a competition between grafting and cross-linking reactions, as the grafted POSS particles reduce the number of available cross-linking sites on the FKM chains (Scheme 2). Indeed, as described in the general introduction, with one functional group, POSS-A can only be grafted onto the matrix. Furthermore, particles with unreacted double bonds could also remain in the matrix and/or potentially react together.

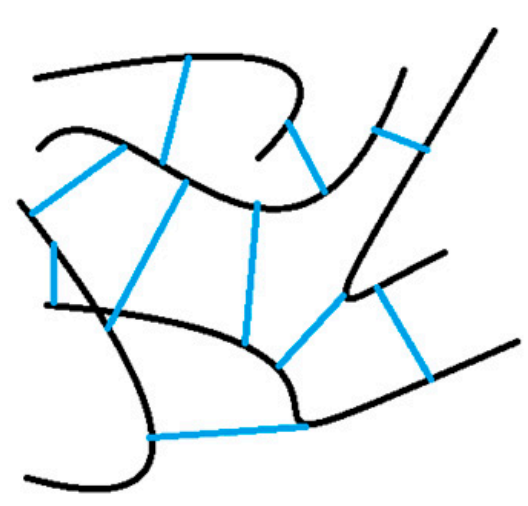

(a)



(b)

Scheme 2. Schema of the crosslinked rubber: (a) without fillers and (b) with POSS-A as pendant groups.

Grafting and cross-linking reactions are yet not straightforward to quantify, as the temperature range of those two phenomena seemed to overlap. Swelling tests were considered. With this technique, unreacted POSS could be released in the swelling solvent and could disturb the interpretation of the experiment by participating to the mass loss. Moreover, with this test, it would be difficult to distinguish the crosslinking reaction part to the grafting reaction.

Figure $4 \mathrm{~b}, \mathrm{c}$ present respectively endothermal peaks at around $50{ }^{\circ} \mathrm{C}, 100^{\circ} \mathrm{C}$, and $150{ }^{\circ} \mathrm{C}$, and at $\sim 225^{\circ} \mathrm{C}$. The intensity of these peaks increased with the increase of filler loading, and was attributed by DSC thermograms performed on the fillers alone, to the fusion of POSS crystal structure (Figure S8). 


\subsubsection{TGA}

The FKM polymer, POSS particles, and samples of composite system $\mathrm{F}_{\mathrm{T}}$ modified with $5-40 \mathrm{phr}$ of POSS were analyzed using TGA under oxidative atmosphere (Figures 5 and 6), and under a non-oxidative (nitrogen) atmosphere (Figures 7-9), in order to characterize the thermal stability of each system.

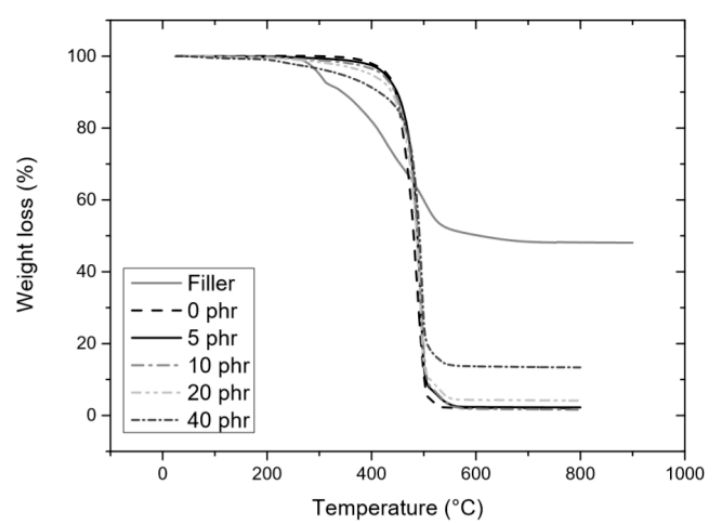

(a)

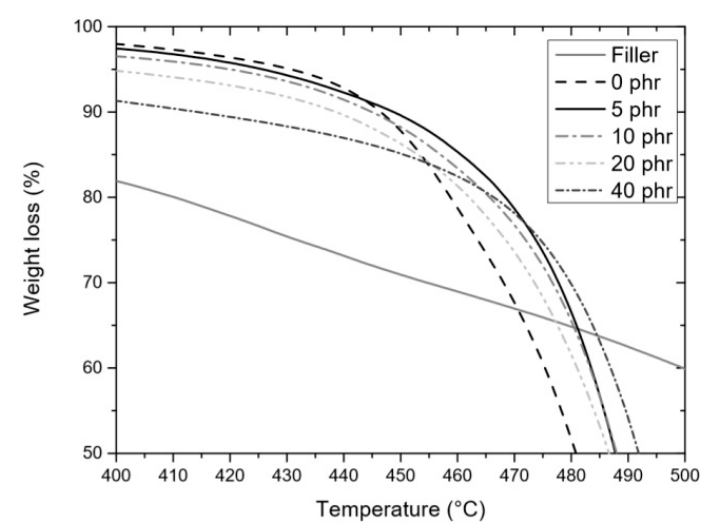

(b)

Figure 5. Thermal Gravimetric Analysis (TGA) curves of POSS-A filler and $\mathrm{F}_{\mathrm{TA}}$ nanocomposites at different filler loading under air. (a) unzoomed; (b) zoomed.

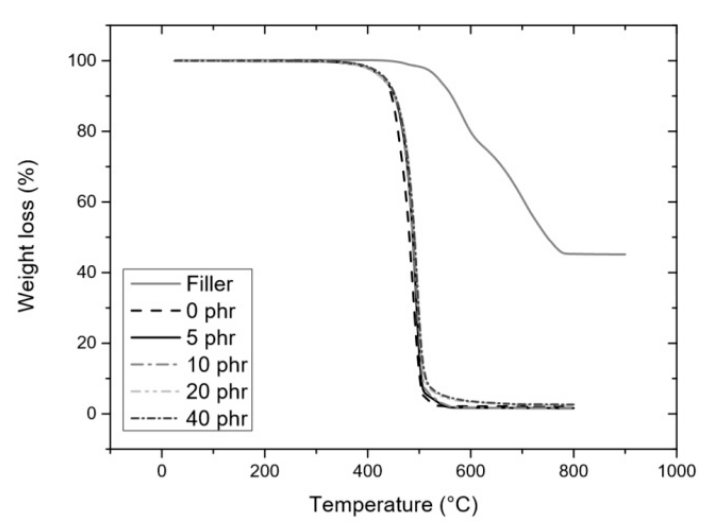

(a)

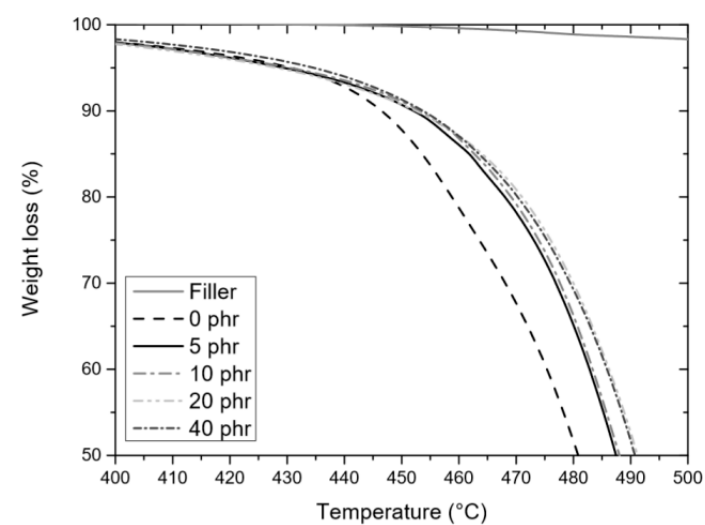

(b)

Figure 6. Thermal Gravimetric Analysis (TGA) curves of POSS-P filler and $\mathrm{F}_{\mathrm{TP}}$ nanocomposites at different filler loading under air. (a) unzoomed; (b) zoomed.

The fluorinated terpolymer matrix exhibits strong thermal stability. The FKM polymer F had a $5 \%$ decomposition temperature equal to $452{ }^{\circ} \mathrm{C}$ under nitrogen, and $398{ }^{\circ} \mathrm{C}$ under air (Figure S9). The addition of a crosslinking system $\left(\mathrm{F}_{\mathrm{R}}\right)$ followed by a vulcanization process increased the thermal properties by $6{ }^{\circ} \mathrm{C}$ under nitrogen, and by $32{ }^{\circ} \mathrm{C}$ under air (Figure S10). The TGA data summarized in Table 2 show that POSS incorporation in polymer matrix can either lead to considerable improvement or decrease of thermal stability as a function of POSS periphery. $T_{5 \%}$ of the various composites was strongly influenced by the thermal stability of the POSS filler itself. Therefore, the temperature at maximum weight loss ( $c a .50 \%$ weight loss in all cases) may provide a more appropriate assessment of thermal stability of the composites as it was likely to mostly reflect the degradation of the FKM network. $T_{\text {onset, }}$ which represents the extrapolated starting temperature, i.e., the beginning of the degradation process involved, is also a common indicator [31]. This criterion takes into consideration the starting decomposition and depends on the degradation speed. 




(a)

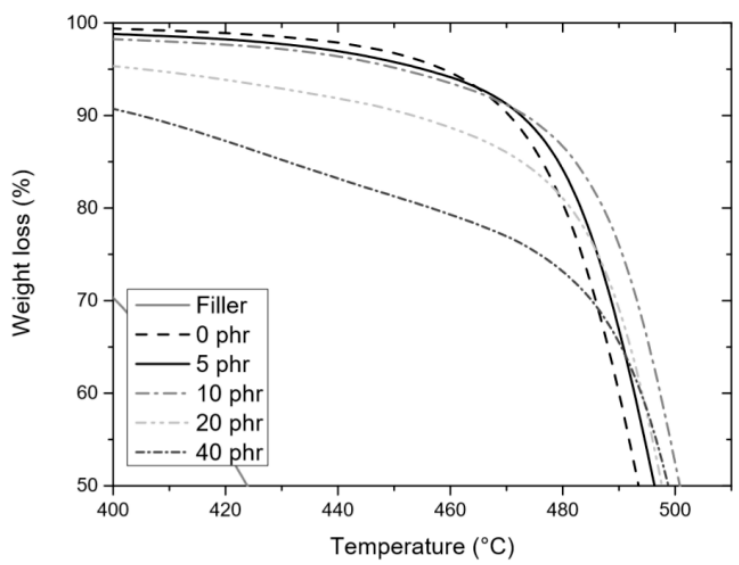

(b)

Figure 7. Thermal Gravimetric Analysis (TGA) curves of POSS-A filler and $\mathrm{F}_{\mathrm{TA}}$ nanocomposites at different filler loading under nitrogen. (a) unzoomed; (b) zoomed.

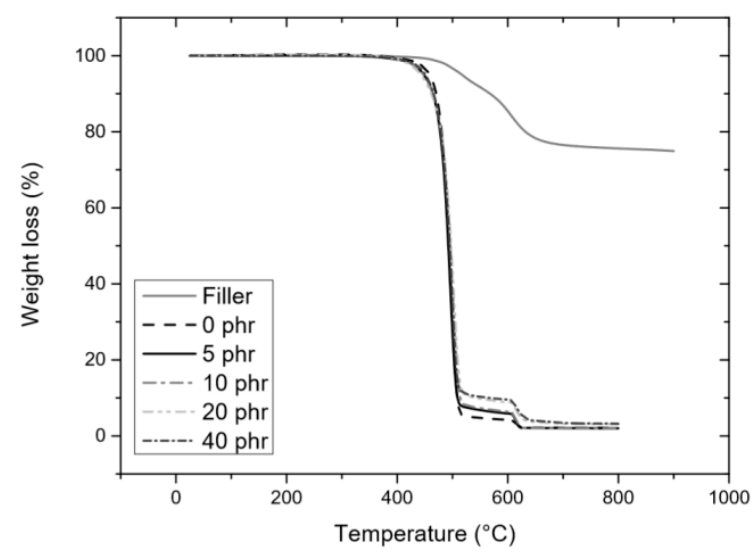

(a)

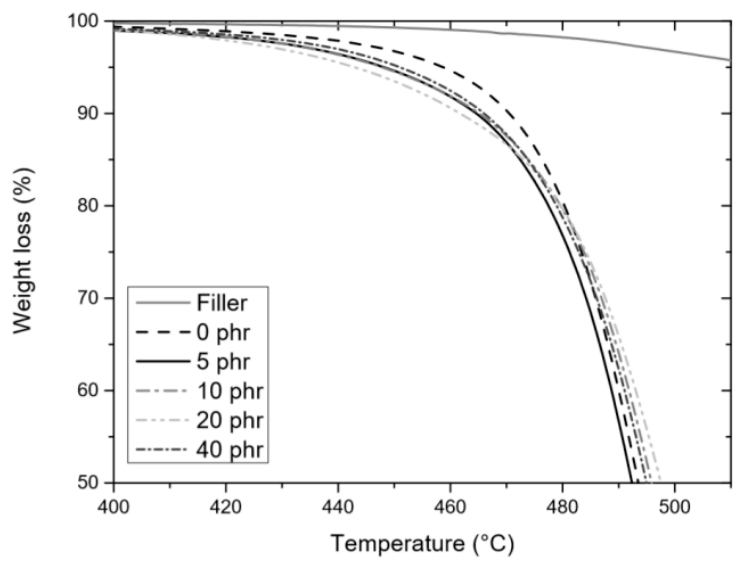

(b)

Figure 8. Thermal Gravimetric Analysis (TGA) curves of POSS-P filler and $\mathrm{F}_{\mathrm{TP}}$ nanocomposites at different filler loading under nitrogen. (a) unzoomed; (b) zoomed.

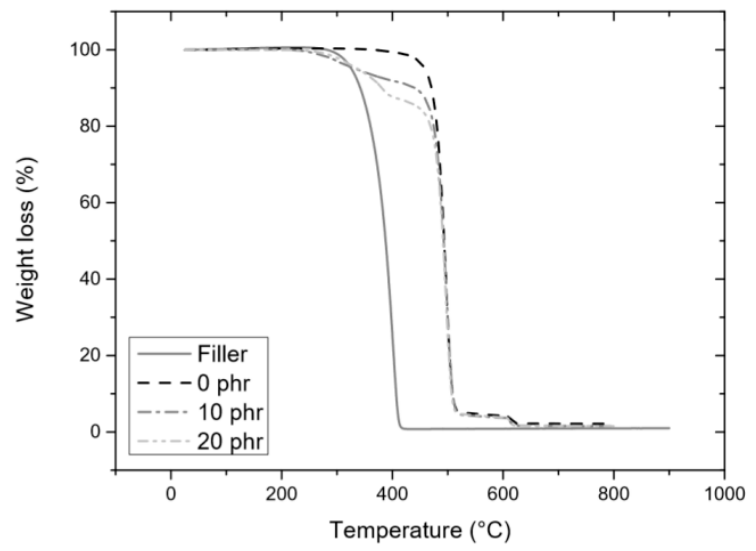

(a)

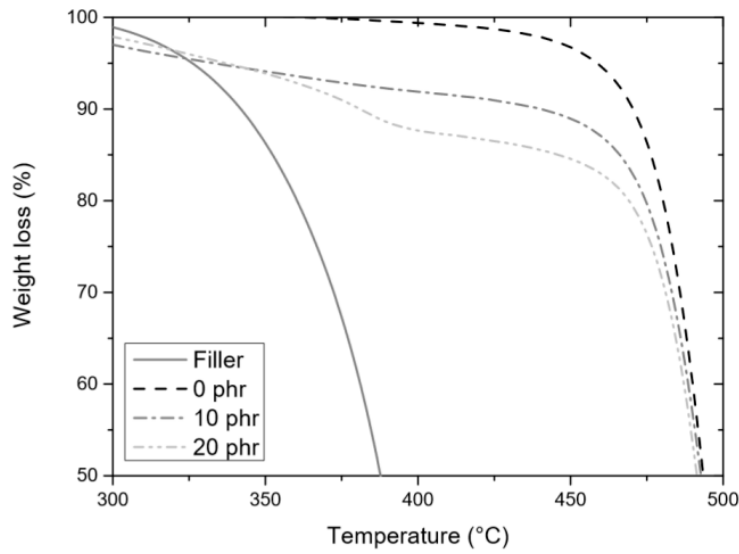

(b)

Figure 9. Thermal Gravimetric Analysis (TGA) curves of POSS-F filler and $\mathrm{F}_{\mathrm{TF}}$ nanocomposites at different filler loading under nitrogen. (a) unzoomed; (b) zoomed. 
Table 2. Summary of TGA results for POSS fillers and nanocomposites.

\begin{tabular}{|c|c|c|c|c|c|c|c|c|}
\hline & \multirow{2}{*}{ phr } & & \multirow{2}{*}{ POSS-A } & \multirow{2}{*}{$\begin{array}{c}F_{R} \\
0\end{array}$} & \multicolumn{4}{|c|}{$\mathrm{F}_{\mathrm{TA}}$} \\
\hline & & & & & 5 & 10 & 20 & 40 \\
\hline \multirow{10}{*}{ Atmosphere } & \multirow{5}{*}{ Nitrogen } & $\mathrm{T}_{\text {onset }}\left({ }^{\circ} \mathrm{C}\right)$ & $371 \pm 4$ & $467 \pm 2$ & $469 \pm 2$ & $474 \pm 3$ & $478 \pm 3$ & $481 \pm 1$ \\
\hline & & $\mathrm{T}_{5 \%}\left({ }^{\circ} \mathrm{C}\right)$ & $321 \pm 3$ & $458 \pm 1$ & $450 \pm 4$ & $449 \pm 2$ & $419 \pm 2$ & $328 \pm 4$ \\
\hline & & $\mathrm{T}_{50 \%}\left({ }^{\circ} \mathrm{C}\right)$ & $432 \pm 1$ & $497 \pm 1$ & $497 \pm 1$ & $501 \pm 1$ & $502 \pm 2$ & $502 \pm 1$ \\
\hline & & Ash (\%) & $3.8 \pm 0.8$ & $1.8 \pm 0.2$ & $2.2 \pm 0.3$ & $2.3 \pm 0.02$ & $3.8 \pm 0.9$ & $5.7 \pm 0.9$ \\
\hline & & Theoretical ash (\%) & & & 0.2 & 0.3 & 0.6 & 1.1 \\
\hline & \multirow{5}{*}{ Air } & $\mathrm{T}_{\text {onset }}\left({ }^{\circ} \mathrm{C}\right)$ & $258 \pm 6$ & $456 \pm 4$ & $465 \pm 1$ & $467 \pm 1$ & $470 \pm 2$ & $474 \pm 2$ \\
\hline & & $\mathrm{T}_{5 \%}\left({ }^{\circ} \mathrm{C}\right)$ & $300 \pm 1$ & $430 \pm 1$ & $426 \pm 1$ & $421 \pm 2$ & $399 \pm 1$ & $336 \pm 2$ \\
\hline & & $\mathrm{T}_{50 \%}\left({ }^{\circ} \mathrm{C}\right)$ & $502 \pm 1$ & $488 \pm 1$ & $493 \pm 1$ & $493 \pm 2$ & $492 \pm 2$ & $493 \pm 3$ \\
\hline & & Ash (\%) & $47.4 \pm 0.9$ & $2.0 \pm 0.1$ & $2.2 \pm 0.08$ & $2.4 \pm 0.2$ & $4.7 \pm 0.4$ & $12.3 \pm 0.8$ \\
\hline & & Theoretical ash (\%) & & & 2.3 & 4.3 & 7.9 & 13.5 \\
\hline & \multirow{2}{*}{ phr } & & \multirow{2}{*}{ POSS-P } & \multirow{2}{*}{1} & \multicolumn{4}{|c|}{$\mathrm{F}_{\mathrm{TP}}$} \\
\hline & & & & & 5 & 10 & 20 & 40 \\
\hline \multirow{12}{*}{ Atmosphere } & \multirow{5}{*}{ Nitrogen } & $\mathrm{T}_{\text {onset }}\left({ }^{\circ} \mathrm{C}\right)$ & $543 \pm 6$ & & $465 \pm 3$ & $468 \pm 3$ & $468 \pm 3$ & $469 \pm 1$ \\
\hline & & $\mathrm{T}_{5 \%}\left({ }^{\circ} \mathrm{C}\right)$ & $518 \pm 1$ & & $450 \pm 3$ & $452 \pm 4$ & $455 \pm 3$ & $452 \pm 1$ \\
\hline & & $\mathrm{T}_{50 \%}\left({ }^{\circ} \mathrm{C}\right)$ & $606 \pm 1$ & & $495 \pm 1$ & $499 \pm 1$ & $501 \pm 1$ & $499 \pm 2$ \\
\hline & & Ash (\%) & $74.7 \pm 0.2$ & & $2.0 \pm 0.1$ & $2.1 \pm 0.01$ & $3.02 \pm 0.9$ & $3.5 \pm 0.5$ \\
\hline & & Theoretical ash (\%) & & & 3.6 & 6.8 & 12.5 & 21.3 \\
\hline & \multirow{5}{*}{ Air } & $\mathrm{T}_{\text {onset }}\left({ }^{\circ} \mathrm{C}\right)$ & $518 \pm 3$ & & $460 \pm 2$ & $459 \pm 1$ & $466 \pm 2$ & $463 \pm 2$ \\
\hline & & $\mathrm{T}_{5 \%}\left({ }^{\circ} \mathrm{C}\right)$ & $538 \pm 1$ & & $428 \pm 1$ & $429 \pm 3$ & $428 \pm 2$ & $434 \pm 1$ \\
\hline & & $\mathrm{T}_{50 \%}\left({ }^{\circ} \mathrm{C}\right)$ & $583 \pm 1$ & & $493 \pm 1$ & $495 \pm 1$ & $496 \pm 1$ & $494 \pm 1$ \\
\hline & & Ash (\%) & $45.3 \pm 0.2$ & & $1.5 \pm 0.06$ & $1.6 \pm 0.1$ & $2.4 \pm 0.1$ & $2.5 \pm 0.2$ \\
\hline & & Theoretical ash (\%) & & & 2.2 & 4.1 & 7.6 & 12.9 \\
\hline & \multirow{2}{*}{ phr } & & \multirow{2}{*}{ POSS-F } & & \multicolumn{4}{|c|}{$\mathrm{F}_{\mathrm{TF}}$} \\
\hline & & & & & & 10 & 20 & \\
\hline \multirow{10}{*}{ Atmosphere } & \multirow{5}{*}{ Nitrogen } & $\mathrm{T}_{\text {onset }}\left({ }^{\circ} \mathrm{C}\right)$ & $361 \pm 6$ & & & $467 \pm 1$ & $470 \pm 1$ & \\
\hline & & $\mathrm{T}_{5 \%}\left({ }^{\circ} \mathrm{C}\right)$ & $331 \pm 2$ & & & $354 \pm 1$ & $317 \pm 2$ & \\
\hline & & $\mathrm{T}_{50 \%}\left({ }^{\circ} \mathrm{C}\right)$ & $405 \pm 6$ & & & $497 \pm 1$ & $497 \pm 1$ & \\
\hline & & Ash (\%) & $0.9 \pm 0.1$ & & & $1.7 \pm 0.2$ & $1.2 \pm 0.3$ & \\
\hline & & Theoretical ash (\%) & & & & 0.1 & 0.2 & \\
\hline & \multirow{5}{*}{ Air } & $\mathrm{T}_{\text {onset }}\left({ }^{\circ} \mathrm{C}\right)$ & $346 \pm 6$ & & & & & \\
\hline & & $\mathrm{T}_{5 \%}\left({ }^{\circ} \mathrm{C}\right)$ & $319 \pm 1$ & & & & & \\
\hline & & $\mathrm{T}_{50 \%}\left({ }^{\circ} \mathrm{C}\right)$ & $396 \pm 6$ & & & & & \\
\hline & & Ash (\%) & $0.06 \pm 0.3$ & & & & & \\
\hline & & Theoretical ash (\%) & & & & & & \\
\hline
\end{tabular}

Both POSS-A and POSS-F exhibited significant weight losses at lower temperatures than did the FKM matrix. The $\mathrm{T}_{5 \%}$ of $\mathrm{F}_{\mathrm{TA}}$ and $\mathrm{F}_{\mathrm{TF}}$ composites consequently decreased upon addition of POSS. While the thermal resistance of POSS-P was better, this did not translate into higher $\mathrm{T}_{5 \%}$ for $\mathrm{F}_{\mathrm{TP}}$. Regardless of the atmosphere, POSS-P decomposed faster and completely in presence of the matrix once the FKM weight loss occurred (Figures 6 and 8), which suggests the release of fluoride anions attacking the POSS silicon cage. The release of hydrofluoric acid upon the degradation of FKM is known to occur through dehydrofluorination, leading to the formation of double carbon bonds on the polymer backbone [7,32]. This was consistent with the char yield reduction. Indeed, POSS decompose ideally to silica form [33]. The theoretical ash (residue percentage) for the total conversion of the POSS cage was calculated (Table 2). The higher residue percentage obtained for POSS-P under nitrogen atmosphere (74.7\%), with respect to inorganic $\mathrm{Si}-\mathrm{O}$ fraction (ca. $40 \% \mathrm{wt}$.) can be attributed to the entrapment of carbon in the structure [34] (Figure 8). $\mathrm{F}_{\mathrm{TP}}$ ashes are clearly lower than the theoretical ash, confirming the elimination of the formation of $\mathrm{SiO}_{2}$ residue [27].

Most importantly, it was noticed that both POSS-A and POSS-P led to higher $\mathrm{T}_{\text {onset }}$ and $\mathrm{T}_{50 \%}$ values. $\mathrm{T}_{\text {onset }}$ increases with the filler loading. $\mathrm{F}_{\mathrm{TA}}$ exhibited better improvement under air than under nitrogen $\left(+18{ }^{\circ} \mathrm{C}\right.$ vs. $+14{ }^{\circ} \mathrm{C}$ at $40 \mathrm{phr}$ with respect to $\left.\mathrm{F}_{\mathrm{R}}\right)$ (Figures 5 and 7$)$. Similarly, in regards of $\mathrm{T}_{\text {onset }}, \mathrm{F}_{\mathrm{TP}}$ seemed to present better thermal resistance under air atmosphere $\left(+10{ }^{\circ} \mathrm{C}\right.$ at $20 \mathrm{phr}$ under air vs. $+2{ }^{\circ} \mathrm{C}$ at $40 \mathrm{phr}$ under nitrogen), as observed with a polystyrene matrix in the literature [35]. This improvement under thermal oxidative environment could be linked to the formation of a silica $\left(\mathrm{SiO}_{2}\right)$ layer on the surface, hence serving as a barrier and preventing further degradation of the matrix [36]. $\mathrm{T}_{50 \%}$ showed a similar trend, with values reaching $493{ }^{\circ} \mathrm{C}\left(+5^{\circ} \mathrm{C}\right)$ and $502{ }^{\circ} \mathrm{C}\left(+5^{\circ} \mathrm{C}\right)$ for 
$\mathrm{F}_{\mathrm{TA}}$ under air and nitrogen, respectively. For $\mathrm{F}_{\mathrm{TP}}, \mathrm{T}_{50 \%}$ up to $496^{\circ} \mathrm{C}\left(+8^{\circ} \mathrm{C}\right)$ and $501^{\circ} \mathrm{C}\left(+4^{\circ} \mathrm{C}\right)$ were determined under air and nitrogen, respectively. Thus, based on the assumption that $\mathrm{T}_{\text {onset }}$ and $\mathrm{T}_{50 \%}$ values provided insights into the degree of decomposition of the FKM network, it can be concluded that POSS-A and POSS-P fillers improved the thermal stability of the nanocomposites. At the same time, no significant enhancement was observed with POSS-F (Figure 9 and Table 2).

\subsection{Mechanical Characterization}

\subsubsection{Tensile Tests}

Given appropriate film forming properties and promising thermal behavior, POSS-A and POSS-P composites were selected for further investigations of their mechanical properties. Measurements were realized without the elimination of Mullins effect [37]. The tensile properties of the compounds were measured at a cross-head speed of $1 \mathrm{~mm} / \mathrm{min}$ (or $\dot{\varepsilon}=0.083 \% / \mathrm{s}$ ) at room temperature (Figure 10). A low rate of deformation was fixed in order to remove the viscosity effect. The values of ultimate tensile stress, elongation at break, modulus at 10\% elongation, and modulus at $100 \%$ elongation for the different nanocomposites are given in Table 3 . These data were chosen to conform to industrial settings.



Figure 10. Stress-strain curves of $\mathrm{F}_{\mathrm{TA}}$ and $\mathrm{F}_{\mathrm{TP}}$ mixtures at 5 and $20 \mathrm{phr}$ at room temperature.

Table 3. Mechanical parameters obtained from tensile tests at room temperature.

\begin{tabular}{cccccc}
\hline Sample & $\mathbf{F}_{\mathbf{R}}$ & \multicolumn{2}{c}{$\mathbf{F}_{\mathrm{TA}}$} & \multicolumn{2}{c}{$\mathrm{F}_{\mathrm{TP}}$} \\
\hline phr & 0 & 5 & 20 & 5 & 20 \\
Modulus at 10\% elongation (MPa) & $0.07 \pm 0.03$ & $0.2 \pm 0.04$ & $0.6 \pm 0.1$ & $0.07 \pm 0.02$ & $0.2 \pm 0.03$ \\
Modulus at 100\% elongation (MPa) & $0.6 \pm 0.05$ & $0.9 \pm 0.08$ & $1.3 \pm 0.09$ & $0.4 \pm 0.06$ & $0.3 \pm 0.02$ \\
Tensile at break (MPa) & $2.4 \pm 0.7$ & $3.23 \pm 0.4$ & $2.6 \pm 0.2$ & $1.2 \pm 0.1$ & $0.5 \pm 0.07$ \\
Elongation at break (\%) & $278.3 \pm 45$ & $286.0 \pm 37$ & $279.2 \pm 25$ & $243.4 \pm 15$ & $180.4 \pm 14$ \\
\hline
\end{tabular}

For $\mathrm{F}_{\mathrm{TA}}$, a significant change in mechanical behavior, characterized by an increase of stiffness at the origin, was evidenced. The ultimate tensile stress increased by $35 \%$, and a slight increase of tensile strain ( $3 \%$ ) was observed at $5 \mathrm{phr}$ in comparison with $\mathrm{F}_{\mathrm{R}}$. The moduli at $10 \%$ and $100 \%$ elongation gradually increased with POSS-A loading. At $20 \mathrm{phr}$, the modulus at $100 \%$ elongation increased by $116 \%$ compared to the compound without fillers, while the tensile at break decreased by $19.5 \%$ versus the 5 phr sample.

On the contrary, incorporation of POSS-P was found to have a negative impact on the mechanical properties of $\mathrm{F}_{\mathrm{TP}}$ samples. The modulus at $10 \%$ of deformation remains relatively unaffected, whereas the modulus at $100 \%$, tensile strength, and elongation at break decreased with increasing particle content (Figure 10). The observed decline relative to $F_{R}$ suggests that micron-sized POSS domains that were observed on Figures 2 and 3 to be due to the aggregation of nanofillers, may behave as 
weakening points during material deformation [30]. Since such micro-aggregates are also present in $\mathrm{F}_{\mathrm{TA}}$ composites, their enhanced mechanical properties can be attributed to specific interactions between FKM polymer chains and POSS-A. This is consistent with the lowering of the temperature, at which the thermal initiation of exothermic reactions occurs (Figure 4a) due to the presence of reactive functional units at the surface of POSS-A particles, as discussed above, and this points toward a critical role of covalent grafting of POSS particles on FKM. In a similar study with one functional group on a POSS cage structure, Pan et al. [21] concluded that the increase of ultimate properties of a PDMS polymer was due to creation of links between the matrix and POSS. It is also worth mentioning here that the maximum tensile and elongation at break were obtained for $\mathrm{F}_{\mathrm{TA}}$ at a $5 \mathrm{phr}$ content, corresponding to the highest level of cross-linking according to DSC thermograms. Therefore, optimized resistance to high stress deformation may result from a trade-off between sufficient grafting and cross-linking density.

\subsubsection{DMA}

Temperature sweeps realized by DMA (Figure 11) allow to determine the glass transition temperature and the rubbery state. Relaxation at high temperatures is associated with a change in the storage modulus, and occurs at a temperature higher to $\mathrm{T}_{\mathrm{g}}$ as measured by DSC, as typically observed in literature [38]. The tan $\delta$ peak curve is commonly used to estimate the $\mathrm{T}_{g}$ [39]. The height (amplitude) of the $\tan \delta$ curve is directly related to a material's ability to dissipate energy through segmental motion, and the width of the peak informs the homogeneity of a system. Indeed, the height of $\tan \delta$ peak is associated with the change in the magnitude of motion, as the amorphous polymer segments undergo a change from a glassy state to a rubbery state [40]. The pertinent parameters are summarized in Table 4.

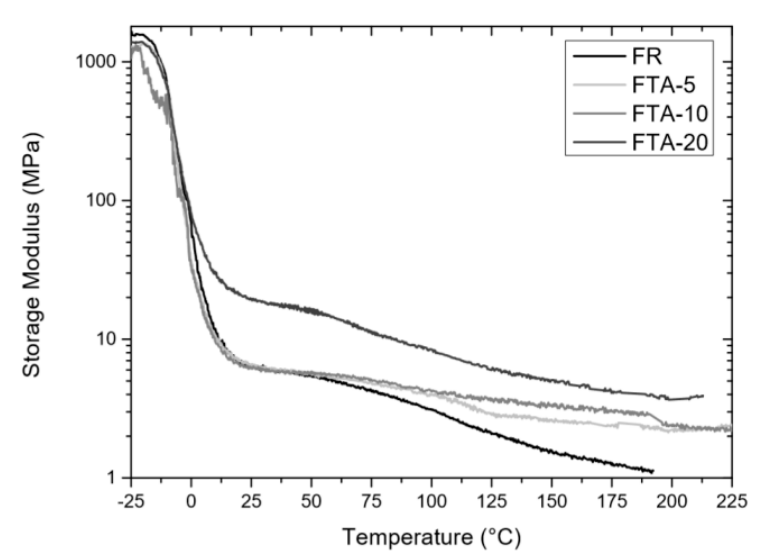

(a)



(c)

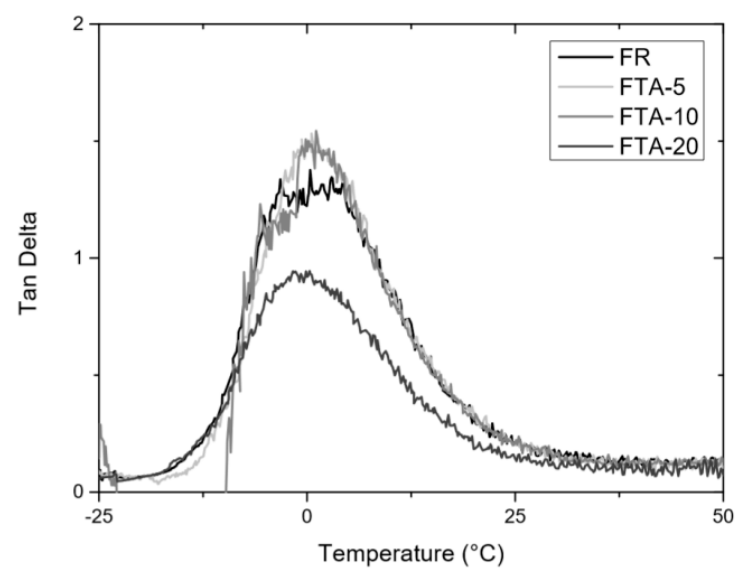

(b)

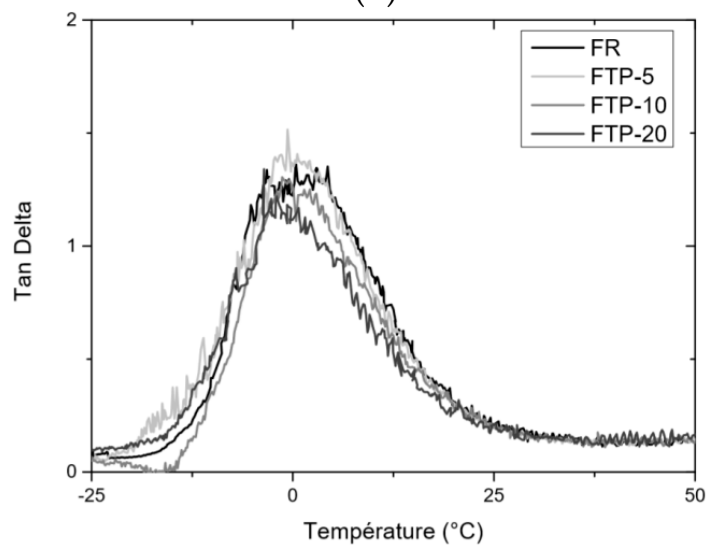

(d)

Figure 11. Temperature sweeps of the $\mathrm{F}_{\mathrm{T}}$ nanocomposites: $(\mathbf{a}, \mathbf{b}) \mathrm{F}_{\mathrm{TP}},(\mathbf{c}, \mathbf{d}) \mathrm{F}_{\mathrm{TA}}$. 
Table 4. Mechanical parameters obtained from tensile tests at room temperature.

\begin{tabular}{|c|c|c|c|c|}
\hline Sample & $\begin{array}{c}\text { Temperature at } \\
\text { the Peak of Tan } \delta \\
\mathrm{T}_{\mathrm{g}}\left({ }^{\circ} \mathrm{C}\right)\end{array}$ & $\begin{array}{c}\text { Tan } \delta \text { at Temperature of } \\
T_{g}\left(T=T_{g}\right) \\
\operatorname{Tan} \delta\end{array}$ & $\begin{array}{c}\text { Storage Modulus } \\
\text { at } 100^{\circ} \mathrm{C} \\
\mathrm{E}^{\prime} 100(\mathrm{MPa})\end{array}$ & $\begin{array}{c}\text { Storage Modulus } \\
\text { at } 200{ }^{\circ} \mathrm{C} \\
\mathrm{E}^{\prime} 200(\mathrm{MPa})\end{array}$ \\
\hline $\mathrm{F}_{\mathrm{R}}$ & $-2.8 \pm 0.2$ & $1.6 \pm 0.09$ & $3.05 \pm 0.3$ & $1.3 \pm 0.4$ \\
\hline $\mathrm{F}_{\mathrm{TA}-05}$ & $1.4 \pm 0.2$ & $1.5 \pm 0.07$ & $4.0 \pm 0.1$ & $2.1 \pm 0.07$ \\
\hline $\mathrm{F}_{\mathrm{TA}-10}$ & $1.5 \pm 0.1$ & $1.4 \pm 0.2$ & $4.8 \pm 0.8$ & $2.7 \pm 0.6$ \\
\hline $\mathrm{F}_{\mathrm{TA}-20}$ & $0.2 \pm 0.07$ & $0.9 \pm 0.01$ & $9.2 \pm 1.6$ & $4.0 \pm 0.6$ \\
\hline $\mathrm{F}_{\mathrm{TP}-05}$ & $-1.8 \pm 0.09$ & $1.5 \pm 0.2$ & $3.9 \pm 0.1$ & $1.8 \pm 0.4$ \\
\hline $\mathrm{F}_{\mathrm{TP}-10}$ & $-0.9 \pm 0.02$ & $1.3 \pm 0.07$ & $4.4 \pm 0.2$ & $2.0 \pm 0.7$ \\
\hline $\mathrm{F}_{\mathrm{TP}-20}$ & $1.1 \pm 0.1$ & $1.05 \pm 0.03$ & $5.6 \pm 0.4$ & $2.4 \pm 0.2$ \\
\hline
\end{tabular}

From the obtained results, two main phenomena were observed here. First, POSS fillers impacted the behavior around the glass transition. A decrease of $\tan \delta$ peak was noticed with increasing amount of POSS (Figure 11b,d). Systems with lower tan $\delta$ peaks had lower ratios of energy, absorbing viscous motions. The decrease in $\tan \delta$ peak height may be caused by more restricted motion dynamics response due to the presence of POSS in the matrix [41]. These observations suggest that the chains movement was hindered by the presence of POSS. For $\mathrm{F}_{\mathrm{TA}}$ and $\mathrm{F}_{\mathrm{TP}}$, the $\mathrm{Tg}$ values were slightly shifted to higher temperatures in comparison with $\mathrm{F}_{\mathrm{R}}$. However, a decrease of $\mathrm{Tg}$ for $\mathrm{F}_{\mathrm{TA}-20}$ was noticed. This may be due to a lower grafting density because of higher POSS-A loading. POSS-A particles could indeed tend to react between themselves instead of grafting onto polymer chains during the vulcanization process.

Secondly, the evolution of storage modulus $E^{\prime}$ in temperature showed a strong improvement upon POSS loading at high temperature (Figure 11a,c and Table 4). The phenomenon was more significant for $\mathrm{F}_{\mathrm{TA}}$ composites. $\mathrm{F}_{\mathrm{TA}-20}$ presented the highest increase of storage modulus $\mathrm{E}^{\prime}$ at 200 ${ }^{\circ} \mathrm{C}\left(+210 \%\right.$ compared with $\mathrm{F}_{\mathrm{R}}$ vs. $+127 \%$ for $\left.\mathrm{F}_{\mathrm{TP}-20}\right)$. Thus, the DMA characteristics suggested less motions of the macromolecular structure in the network and confirmed that POSS grafting could play a significant role. Formation of rigid fillers network usually provided additional levels of reinforcement. Filler-matrix and filler-filler interactions are unanimously associated with the decrease of the dynamic modulus with the strain amplitude, which is known as the Payne effect. This reinforcement has been highlighted in a previous study [42]. The enhanced values of $\mathrm{E}^{\prime}$ in the rubbery plateau region indicated that POSS-A may be a particularly suitable reinforcing filler in fluoroelastomers for high temperature applications.

\section{Conclusions}

Three POSS nanofillers have been incorporated in a FKM matrix. The nanocomposites were obtained as thin films. SEM/TEM and EDX imaging reveal a relatively proper dispersion state with the presence of micron-sized POSS domains that are smaller than aggregates that are attributed to the cross-linking system. The influence of POSS peripheric substituents and POSS content on thermal and thermomechanical properties has been studied. Although POSS fillers have little influence on the glass transition temperature, they are found to interfere with the vulcanization process. In particular, DSC measurements show that POSS-P hampers the cross-linking reaction, whereas the appearance of a new exothermic peak at lower temperature along with increased heat of reaction are indicative of the covalent grafting of POSS-A onto the FKM network. Both $\mathrm{F}_{\mathrm{TA}}$ and $\mathrm{F}_{\mathrm{TP}}$ composites exhibit improved thermal stability, with $50 \%$ weight loss temperature values reaching $493^{\circ} \mathrm{C}$ and $502{ }^{\circ} \mathrm{C}$ for $\mathrm{F}_{\mathrm{TA}}$ under air and nitrogen, respectively $\left(+5{ }^{\circ} \mathrm{C}\right.$ vs. the unfilled FKM matrix). Based on film morphology and thermal properties of the composites, POSS-A and POSS-P are selected as the most appropriate fillers. Incorporation of fillers leads to increased modulus. Consequently, the increase of stiffness leads to a decrease of mechanical response of $\mathrm{F}_{\mathrm{TP}}$ composites because of the hindrance of chains motion induced by the presence of POSS particles. Yet, covalent grafting of POSS is found to play a critical role on the enhancement of mechanical properties of the composites. The maximum tensile and elongation at break 
are obtained for $\mathrm{F}_{\mathrm{TA}}$ with $5 \mathrm{phr}$ of filler and seem to be correlated to a trade-off between cross-linking and grafting density. Furthermore, storage modulus $\mathrm{E}^{\prime}$ is strongly enhanced in the rubbery plateau region up to $4.0 \mathrm{MPa}$ at $200{ }^{\circ} \mathrm{C}$ with $20 \mathrm{phr}$ loading ( $+210 \%$ compared with $\left.\mathrm{F}_{\mathrm{R}}\right)$. Thus, POSS-A appears as a promising reinforcing agent in fluoroelastomers for high temperature applications.

Experiments are under way to further improve the dispersion prior to film deposition. To highlight a more pronounced impact of POSS ability to increase the thermal properties, tensile tests after thermal aging at high temperature and kinetics modelling of degradation are also in progress. Works are in progress to optimize the thermal and mechanical properties of composites FKM/POSS-A bearing various numbers of acrylate functional groups to study more deeply the effect of the grafting versus crosslinking reactions between POSS and FKM matrix.

Supplementary Materials: The following are available online at http:/ / www.mdpi.com/1996-1944/11/8/1358/ s1, Figure S1: SEM micrographs of FKM polymer film (F), Figure S2: SEM micrographs of FR film, Figure S3: TEM micrographs of (a) POSS-A, (b) POSS-P, and (c) POSS-F nanoparticles, Figure S4: TEM micrographs of FKM polymer film (F), Figure S5: TEM micrographs of FR film, Figure S6: EDX spectrum of the black zone observed in Figure S5, for FR mixture, Figure S7: EDX spectrum of the black zone observed in Figure S5, for FR mixture, Figure S8: DSC curves of POSS nanofillers: (a) POSS-A, (b) POSS-P and (c) POSS-F, Figure S9: TGA curves of FKM polymer (F) under air and nitrogen, Figure S10: TGA curves of $F_{R}$ under air and nitrogen.

Author Contributions: Methodology, D.B., M.-P.D. and N.B.; Investigation, D.B.; Validation, M.-P.D., F.L., S.M., N.B., B.S., F.T.-V.; Resources, M.V.; Writting-Original Draft Preparation, D.B., M.-P.D. and N.B.; Writing-Review \& Editing, D.B., M.-P.D., N.B., B.S., F.T.-V., F.L., S.M., Y.T. and E.P.; Supervision, E.P., Y.T., F.T.-V. and S.M.

Funding: This research received no external funding.

Acknowledgments: The authors acknowledge Sonia Georgeault of the Laboratoire de biologie cellulaire et microscopie électronique (Plateforme IBiSA de Microscopie Electronique, Université de Tours et CHRU de Tours) for help with SEM/TEM experiments and measurements. We also thank the CERMEL (Centre d'Etude et de Recherche sur les Matériaux ELastomères) for the access to the equipment required to the realization of the thermomechanical experiments.

Conflicts of Interest: The authors declare no conflict of interest.

\section{References}

1. Améduri, B.; Boutevin, B.; Kostov, G. Fluoroelastomers: Synthesis, properties and applications. Prog. Polym. Sci. 2001, 26, 105-187. [CrossRef]

2. Moore, A.L. Fluoroelastomers Handbook: The Definitive User's Guide; William Andrew Publishing: Norwich, UK, 2006; pp. 25-125.

3. Rhein, R.A. Thermally stable elastomers: A review, California. 1983. Available online: http://www.dtic.mil/ docs / citations / ADA137914 (accessed on 15 September 2015).

4. Ameduri, B.; Boutevin, B. Update on fluoroelastomers: From perfluoroelastomers to fluorosilicones and fluorophosphazenes. J. Fluor. Chem. 2005, 126, 221-229. [CrossRef]

5. Drobny, J.G. Fluoropolymers in automotive applications. Polym. Adv. Technol. 2007, 18, 117-121. [CrossRef]

6. Sugama, T.; Pyatina, T.; Redline, E.; McElhanon, J.; Blankenship, D. Degradation of different elastomeric polymers in simulated geothermal environments at $300{ }^{\circ}$ C. Polym. Degrad. Stab. 2015, 120, 328-339. [CrossRef]

7. Mitra, S.; Ghanbari-Siahkali, A.; Kingshott, P.; Almdal, K.; Kem Rehmeier, H.; Christensen, A.G. Chemical degradation of fluoroelastomer in an alkaline environment. Polym. Degrad. Stab. 2004, 83, 195-206. [CrossRef]

8. Koo, J.H. Processing, Characterisation and Applications. In Polymer Nanocomposites; McGraw-Hill: New York, NY, USA, 2006; pp. 1-239. ISBN 9780071458214.

9. Zimmermann, H.; Schuster, R.H. Advanced dispersion strategies and property design for CNT/Rubber Nanocomposites. World J. Eng. 2011, 1369-1370.

10. Hassar, M. Influence des Nano-Charges de Noir de Carbone sur le Comportement Mécanique de Matériaux Composites: Application au Blindage Electromagnétique. Ph.D. Thesis, Technology University of Compiègne, Compiègne, France, 2013.

11. Arroyo, M.; López-Manchado, M.; Herrero, B. Organo-montmorillonite as substitute of carbon black in natural rubber compounds. Polymer 2003, 44, 2447-2453. [CrossRef] 
12. Feher, F.J.; Wyndham, K.D.; Soulivong, D.; Nguyen, F. Syntheses of highly functionalized cube-octameric polyhedral oligosilsesquioxanes. J. Chem. Soc. Dalt. Trans. 1999, 0, 1491-1498. [CrossRef]

13. Scott, D.W. Thermal rearrangement of branched-chain methylpolysiloxanes 1. J. Am. Chem. Soc. 1946, 68, 356-358. [CrossRef]

14. Li, F.; Wang, J.; Xie, T.; Wang, D.; Tang, J.; Tang, X. Synthesis and study of a new polyorganophosphazene. J. Appl. Polym. Sci. 2001, 80, 1446-1451. [CrossRef]

15. Wu, J.; Mather, P.T. POSS polymers: Physical properties and biomaterials applications. Polym. Rev. 2009, 49, 25-63. [CrossRef]

16. Deng, Y. Study on RAFT Polymerization and Nano-Structured Hybrid System of POSS Macromers. Ph.D. Thesis, INSA (Institut national des science appliqué), University of Lyon, Lyon, France, 2012.

17. Laik, S. Investigation of Polyhedral Oligomeric Silsesquioxanes for Improved Fire Retardancy of Hybrid Epoxy-Based Polymer Systems. Ph.D. Thesis, INSA (Institut national des science appliqué), University of Lyon, Lyon, France, 2014.

18. Blanco, I.; Bottino, F.A.; Cicala, G.; Latteri, A.; Recca, A. A kinetic study of the thermal and thermal oxidative degradations of new bridged POSS/PS nanocomposites. Polym. Degrad. Stab. 2013, 98, 2564-2570. [CrossRef]

19. Li, H.; Yu, D.; Zhang, J. A novel and facile method for direct synthesis of cross-linked polysiloxanes by anionic ring-opening copolymerization with $\mathrm{Ph}_{12}-\mathrm{POSS} / \mathrm{D}_{4} / \mathrm{Ph}_{8} \mathrm{D}_{4}$. Polymer 2005, 46, 5317-5323. [CrossRef]

20. Liu, Y.; Shi, Y.; Zhang, D.; Li, J.; Huang, G. Preparation and thermal degradation behavior of room temperature vulcanized silicone rubber-g-polyhedral oligomeric silsesquioxanes. Polymer 2013, 54, 6140-6149. [CrossRef]

21. Pan, G.; Mark, J.E.; Schaefer, D.W. Synthesis and characterization of fillers of controlled structure based on polyhedral oligomeric silsesquioxane cages and their use in reinforcing siloxane elastomers. J. Polym. Sci. Part B Polym. Phys. 2003, 41, 3314-3323. [CrossRef]

22. Yang, D.; Zhang, W.; Yao, R.; Jiang, B. Thermal stability enhancement mechanism of poly (dimethylsiloxane) composite by incorporating octavinyl polyhedral oligomeric silsesquioxanes. Polym. Degrad. Stab. 2013, 98, 109-114. [CrossRef]

23. Chen, D.; Liu, Y.; Zhang, H.; Zhou, Y.; Huang, C.; Xiong, C. Influence of polyhedral oligomeric silsesquioxanes (POSS) on thermal and mechanical properties of polydimethylsiloxane (PDMS) composites filled with fumed silica. J. Inorg. Organomet. Polym. Mater. 2013, 23, 1375-1382. [CrossRef]

24. Zhang, Y.; Mao, Y.; Chen, D.; Wu, W.; Yi, S.; Mo, S.; Huang, C. Synthesis and characterization of addition-type silicone rubbers (ASR) using a novel cross linking agent PH prepared by vinyl-POSS and PMHS. Polym. Degrad. Stab. 2013, 98, 916-925. [CrossRef]

25. Zhao, Y.; Jiang, X.; Zhang, X.; Hou, L. Toughened elastomer/polyhedral oligomeric silsesquioxane (POSS)-intercalated rectorite nanocomposites: Preparation, microstructure, and mechanical properties. Polym. Compos. 2017, 38, E443-E450. [CrossRef]

26. Sahoo, S.; Bhowmick, A.K. Polyhedral oligomeric silsesquioxane (POSS) nanoparticles as new crosslinking agent for functionalized rubber. Rubber Chem. Technol. 2007, 80, 826-837. [CrossRef]

27. Seurer, B.; Coughlin, E.B. Fluoroelastomer copolymers incorporating polyhedral oligomeric silsesquioxane. Macromol. Chem. Phys. 2008, 209, 2040-2048. [CrossRef]

28. Asim, N.; Ahmadi, S.; Alghoul, M.A.; Hammadi, F.Y.; Saeedfar, K.; Sopian, K. Research and development aspects on chemical preparation techniques of photoanodes for dye sensitized solar cells. Int. J. Photoenergy 2014, 2014, 1-21. [CrossRef]

29. Wu, J.; Haddad, T.S.; Mather, P.T. Vertex group effects in entangled polystyrene-polyhedral oligosilsesquioxane (POSS) copolymers. Macromolecules 2009, 42, 1142-1152. [CrossRef]

30. Ayandele, E.; Sarkar, B.; Alexandridis, P. Polyhedral oligomeric silsesquioxane (POSS)-containing polymer nanocomposites. Nanomaterials 2012, 2, 445-475. [CrossRef] [PubMed]

31. Wagner, M. Termal Analysis in Practice, METTLER TOLEDO Collected Applications Handbook; Mettler-Tolledo: Schwerzenbach, Switzerland, 2013; pp. 30-326.

32. Banik, I.; Bhowmick, A.K.; Raghavan, S.V.; Majali, A.B.; Tikku, V.K. Thermal degradation studies of electron beam cured terpolymeric fluorocarbon rubber. Polym. Degrad. Stab. 1999, 63, 413-421. [CrossRef]

33. Cordes, D.B.; Lickiss, P.D.; Rataboul, F. Recent developments in the chemistry of cubic polyhedral oligosilsesquioxanes. Chem. Rev. 2010, 110, 2081-2173. [CrossRef] [PubMed] 
34. Fina, A.; Tabuani, D.; Carniato, F.; Frache, A.; Boccaleri, E.; Camino, G. Polyhedral oligomeric silsesquioxanes (POSS) thermal degradation. Thermochim. Acta 2006, 440, 36-42. [CrossRef]

35. Blanco, I.; Bottino, F.A.; Cicala, G.; Latteri, A.; Recca, A. Synthesis and characterization of differently substituted phenyl hepta isobutyl-polyhedral oligomeric silsesquioxane/polystyrene nanocomposites. Polym. Compos. 2014, 35, 151-157. [CrossRef]

36. Zheng, L.; Farris, R.J.; Coughlin, E.B. Novel polyolefin nanocomposites: Synthesis and characterizations of metallocene-catalyzed polyolefin polyhedral oligomeric silsesquioxane copolymers. Macromolecules 2001, 34, 8034-8039. [CrossRef]

37. Diani, J.; Fayolle, B.; Gilormini, P. A review on the Mullins effect. Eur. Polym. J. 2009, 45, 601-612. [CrossRef]

38. Wu, J.; Huang, G.; Wang, X.; He, X.; Zheng, J. Detecting different modes of molecular motion in polyisobutylene and chlorinated butyl rubber by using dielectric probes. Soft Matter. 2011, 7, 9224-9230. [CrossRef]

39. Chang, M.C.O.; Thomas, D.A.; Sperling, L.H. Characterization of the area under loss modulus and tan $\delta$-temperature curves: Acrylic polymers and their sequential interpenetrating polymer networks. J. Appl. Polym. Sci. 1987, 34, 409-422. [CrossRef]

40. Epoxy Adhesive Application Guide, Billerica, n.d. Available online: http://www.epotek.com/site/files / brochures/pdfs/adhesive_application_guide.pdf (accessed on 14 September 2017).

41. Fu, B.X.; Lee, A.; Haddad, T.S. Styrene-butadiene-styrene triblock copolymers modified with polyhedral oligomeric silsesquioxanes. Macromolecules 2004, 37, 5211-5218. [CrossRef]

42. Berthier, D.; Deffarges, M.P.; Lacroix, F.; Berton, N.; Schmaltz, B.; Tendron, Y.; Pestel, E.; Tran Van, F.; Meo, S. Nanoparticles effects on the thermomechanical properties of a fluoroelastomer. In Proceedings of the 10th European Conference on Constitutive Models for Rubber (ECCMR X), Munich, Germany, 28-31 August 2017; Lion \& Joh, Taylor \& Francis Group: London, UK, 2017.

(C) 2018 by the authors. Licensee MDPI, Basel, Switzerland. This article is an open access article distributed under the terms and conditions of the Creative Commons Attribution (CC BY) license (http:/ / creativecommons.org/licenses/by/4.0/). 